\title{
Knowledge-sharing and collaborative behaviour: An empirical study on a Portuguese higher education institution
}

Journal of Information Science $1-18$

(C) The Author(s) 2019 Article reuse guidelines: sagepub.com/journals-permissions DOI: 10.1 | 77/016555 I519860464 journals.sagepub.com/home/jis (SAGE

\author{
Marcello Chedid \\ Department of Economics, Management, Industrial Engineering and Tourism (DEGEIT), University of Aveiro, Aveiro, Portugal
}

\section{Ana Caldeira}

Department of Economics, Management, Industrial Engineering and Tourism (DEGEIT), University of Aveiro, Aveiro, Portugal

\section{Helena Alvelos}

Department of Economics, Management, Industrial Engineering and Tourism (DEGEIT) and CIDMA, University of Aveiro, Aveiro, Portugal

\section{Leonor Teixeira}

Department of Economics, Management, Industrial Engineering and Tourism (DEGEIT), IEETA and GOVCOPP, University of Aveiro, Aveiro, Portugal

\begin{abstract}
Collaboration has been considered a way to address the challenges of the 2 Ist century, fostering the necessary innovation, growth and productivity for all parties involved. Several studies reveal that collaboration can be strongly influenced by knowledge sharing. The literature suggests that this topic is quite relevant and that there is an evident lack of empirical studies that properly investigate the relationship between knowledge-sharing and collaborative behaviour in Higher Education Institutions (HEls). In this context, the purpose of this work is to examine whether knowledge-sharing intention has a positive relationship with collaborative behaviour among professors and researchers in a public Portuguese $\mathrm{HEl}$, taking into account other constructs that can have effect on the knowledgesharing intention. In order to reach this objective, a conceptual research model was developed based on the theory of reasoned action. The empirical study was conducted based on a questionnaire, and the data analysis was performed using partial least squares. The results indicate that intrinsic motivation and networking are the factors that positively affect the attitude towards knowledge sharing. Nevertheless, it is concluded that trust is the variable that more strongly affects the knowledge-sharing intention. Finally, the study identified that knowledge-sharing intention has a positive influence in collaborative behaviour. It is considered that this study can contribute to support institutions' management in defining strategies and developing actions in order to promote an organisational culture based on knowledge management that significantly leads to knowledge-sharing and collaboration relationships.
\end{abstract}

\section{Keywords}

Collaborative behaviour; higher education institutions; knowledge sharing; partial least squares; theory of reasoned action

\section{Introduction}

Higher education institutions (HEIs) are knowledge-intensive organisations [1] where knowledge is simultaneously their input and their output [2]. Despite knowledge sharing being one of their core missions [3], studies show that it does not emerge strongly within HEIs [4]. The values and practices associated with knowledge sharing within this context are complex: this is due to the particular characteristics of this type of institutions, such as an individualistic culture,

\section{Corresponding author:}

Marcello Chedid, Department of Economics, Management, Industrial Engineering and Tourism (DEGEIT), University of Aveiro, Campus Universitário de Santiago, 3810-193 Aveiro, Portugal.

Email: mchedid@ua.pt 
knowledge being held as property and source of differentiation, the specific needs of researchers and academic freedom [5-7]. However, knowledge sharing is necessary to integrate the different disciplines, ideas and the knowledge of each different member of the institution [8]. In addition, knowledge sharing holds organisation together, helps communities of people work collaboratively and increases the ability to achieve individual as well as organisational goals [9].

On the contrary, collaboration refers to the relationship and high level of knowledge sharing between team members [8], and is the creation base for new knowledge [8,10].

Since the end of the last century, factors such as globalisation, increasing competition and fast technological advances make the environments of organisations with impact on the life cycle of processes, products and services [11,12] more complex. Knowledge also becomes more complex and not all the organisations have enough resources to manage it $[13,14]$. In this scenario, so they can respond to new challenges, organisations need to identify partners, with the collaboration relationship representing a key resource in promoting innovation [15], technological development [15-18] and a positive impact on their productivity and competitiveness [16]. Like in the business sector, HEIs should encourage and promote internal and external collaboration. Collaboration relationships, besides the creation of new knowledge, may result in publications, dissemination of research results, a decrease in the redundancy of research efforts, and consequently lead to academic productivity $[8,19]$. Furthermore, strategies to promote the sharing of knowledge and collaboration are important requirements that contribute for the overall result being greater than the sum of its parts [20].

There is limited previous research within the context of HEIs concerning this subject [2,3,21]. However, the main studies on knowledge sharing within the context of HEIs have been carried out in the United Kingdom and in Asian countries [22]. Clearly, only few studies have been conducted in Europe, particularly in Portuguese institutions. In a recent study, Al-Kurdi et al. [23] claim that 'other regions and countries must invest in quality research in this area, as it is essential for the development of a nation's higher education system'.

Conceptually following the theory of reasoned action (TRA), this present study proposes that the collaborative behaviour (within the institution and with other organisations) of HEIs members is affected by individual knowledge-sharing intention. Although the TRA has been widely used [24], this study introduces two important aspects into the research model. First, this study includes the motivational factors (intrinsic and extrinsic) studied by Lin [25], and networking applied by Jolaee et al. [26] and Kim and Lee [27], as antecedents of the attitude. Second, in addition to the dimensions attitude and the subjective norm used to interpret the intention, the study also analyzes trust [10] as another significant dimension of intention.

This work presents the findings of an empirical study carried out with professors and researchers of a Portuguese HEI and has as its main objective to examine and analyse whether the knowledge-sharing intention has a positive relationship with collaborative behaviour. It should be emphasised that knowledge-sharing intention can be affected by other factors, also studied in this context. Data analysis will be performed using partial least squares (PLS).

\section{Theoretical background}

\section{I. Knowledge sharing in HEls}

Knowledge is dynamic and it is not a useful resource by itself [28], unless it is shared in order to be used and evolved. Knowledge sharing is a fundamental process of making individual knowledge, ideas, experiences or technologies available through the conversion into a manner that can be understood and used by other individuals or communities $[2,24]$. This process can occur via written form, through documentation and systematisation of knowledge, or in a social context through networking with other stakeholders. Knowledge sharing is associated with the collaboration process, since it is possible to leverage and create new knowledge, solutions, process or products through it $[10,21,29]$.

HEIs are recognised as knowledge-intensive organisation [1,3], composed of a group of individual experts, which are simultaneously developers, users and holders of knowledge [30], with a high degree of specialisation in certain disciplines, which are organised into different scientific domains [6]. Throughout their history, HEIs have played a crucial role in creating and disseminating knowledge [31]. HEIs have experienced intensified pressure [30], influenced by the knowledge society and the internationalisation of institutions, where knowledge, creativity, innovation and entrepreneurship emerge as essential elements for competitiveness. On the contrary, this pressure demands a new attitude towards knowledge sharing from the HEIs in general, and their main actors (e.g. professors and researchers).

In this environment, it is expected that knowledge is shared freely among their members, since knowledge sharing is fundamental in integrating different disciplines, ideas and knowledge possessed by the different HEIs' actors [4]. However, HEIs' members generally place a higher priority on individual goals [29], consider knowledge as their property [10] and put more emphasis on knowledge creation rather than on knowledge sharing [29]. With this individualistic model, knowledge sharing in HEIs quite often means to break down some silos of knowledge, offering very little chance 
for collaboration [1]. Another important point of the impact of knowledge sharing among HEIs' members is the current high degree of specialisation of disciplines caused by the increased rate of innovation, which may lead towards the decline of involvement and the lessening of social ties with disciplinary and institutional colleagues [32]. Some authors also consider that national culture has a meaningful impact on institutional culture $[23,33]$.

In the present study, the survey is focused on knowledge that is related to the expertise and know-how of HEIs members (professors and researchers), which is comprised of educational knowledge (i.e. teaching materials, teaching methodologies and programme contents) and scientific knowledge (i.e. scientific materials, research results and scientific publications).

\subsection{Collaboration in HEls}

Collaboration is the willingness to work together in order to search solutions and to accomplish outcomes that go beyond the limited vision of each individual concerned party [29,34]. Collaboration has been considered a way to address the challenges of the 21 st century, fostering the necessary innovation, growth and productivity for all parties involved. In Grays' [34] opinion, collaboration is based on the simple adages of 'two heads are better than one', where different points of view about existing problem-solving can often be the source of immense creative potential. However, according to the observation of some authors, collaboration itself is not a solution [34], but an enabler in bringing about added value. Currently, collaboration is viewed as a critical competence for organisations [35]. That said, it is not always easy to involve difficult issues, such as processes not clearly defined or management difficulties $[34,35]$. To collaborate successfully, considerable effort is necessary [34]. One needs to understand and develop a behavioural approach, embracing all relevant interested parties and making it possible to establish a strong linkage and a high level of knowledge sharing between teams [8].

The scenario of the last few years required a focus shift from inter-organisational collaboration to intra-organisational collaboration [36], for the purpose of achieving other sources of resources, knowledge and needed skills [37].

The literature regarding the collaboration in HEIs highlights that 'collaboration is characterized by strong pragmatism and a high degree of self-organisation' [19], and that its members collaborate when necessary, configuring itself as a weak point in this kind of organisation [38,39]. In general, HEIs members emphasise self-study more and they are not always aware of the valuable expertise within the HEIs that can contribute to their work, preferring instead to achieve their goals and objectives independently and individually $[1,29,38]$. Collaboration activities can result in publications, dissemination of research results, the creation of new knowledge, and consist an important source of career advancement, reputation and self-empowerment of the members (professors and researchers) of HEIs [40].

Collaboration also leads to a decrease in the redundancy of research efforts and an increase in resource savings, reducing the costs for research [41]. Considering the preconditions for successful collaboration addressed by Diamond and Rush [35], such as 'a more holistic approach to problem-solving (less rule and status bound), and a more open approach to discussion and problem-solving', it is expected that HEIs are a special context so that collaboration can be successful.

\section{Research model and hypotheses}

The conceptual research model is developed based on the TRA theory formulated by Fishbein and Ajzen [42]. TRA is a well-known theory used to predict and explain individual behaviour [25], and has been applied to examine knowledgesharing intention under different contexts [43]. According to Ajzen and Fishbein [44], 'specific behaviors are guided largely by a reasoned action approach that assumes that people's behaviour follows reasonably from their beliefs, attitudes, and intentions'. From this perspective, the TRA is based on the premise that an individual's behaviour is determined by his or her behavioural intention to perform it. This intention is itself determined by the individual's attitudes and his or her subjective norms towards the behaviour [42].

Conceptually following the TRA, this study applies a framework (Figure 1), which proposes that collaborative behaviour (within the institution and with other organisations) of HEIs members is affected by the individual knowledgesharing intention. Although the TRA has been widely used, this study introduces two important aspects into the research model. First, according to the Wang and Noe's [24] statement, few studies have examined attitude antecedents, and Lin [25] alerts to the 'need to include other components to provide a broader view and a better explanation of human behaviors'. Thus, this study includes the motivational factors (intrinsic and extrinsic) studied by Lin [25], and networking applied by Jolaee et al. [26] and Kim and Lee [27], as antecedents of the attitude. Motivation means being energised or activated towards an end, and 'orientation of motivation concerns the underlying attitudes and goals that give rise to action' [45]. Whereas networking has a significant effect on the attitude towards knowledge sharing, as highlighted in the Wang and Noe's [24] literature review where individuals 'do not work, learn, or share knowledge in isolation, but 


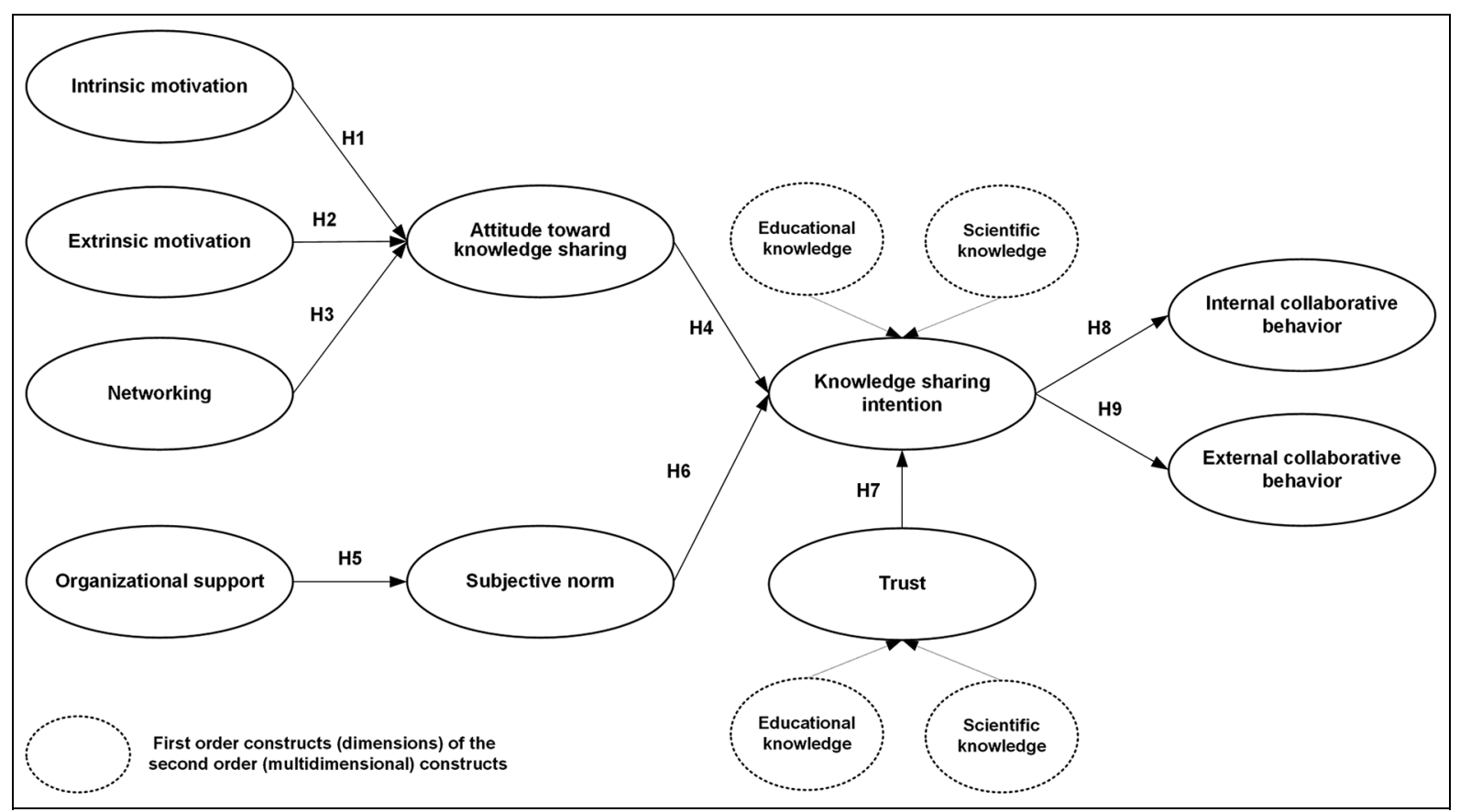

Figure I. The research model.

are embedded in social networks'. Second, in addition to the dimensions attitude and subjective norm used to interpret the intention, the study also analyzes trust [10] as another significant dimension of intention. It is presupposed that the knowledge-sharing intention requires trust [33], since trust plays an important role in the knowledge-sharing process among members of institutions [40].

Since the national issues seem to be important in such analysis [33], the authors stress that no study was found in the literature that had examined and analysed the knowledge-sharing intention effects on the collaboration behaviour in Portuguese HEI.

Each construct involved in the basis of research hypotheses and the design of the questionnaire is discussed ahead.

\section{I. Intrinsic motivation}

Intrinsic motivation behaviour is based on the individuals' need to be competent and autonomous [46]. Intrinsic motivation will occur only for activities that hold intrinsic interest for an individual; in other words, activities that are performed out of interest and to satisfy individuals' need for competence (self-efficacy) and autonomy (self-determining) [43]. Studies have shown the role of intrinsic motivational factors in explaining individual behaviour in several domains $[45,46]$, including knowledge sharing [25,47]. This study proposes that knowledge, self-efficacy and enjoyment in helping others as intrinsic factors that motivate towards knowledge sharing in HEIs. According to social cognitive theory, knowledge self-produced factors influences an individual's attitude and behavior [48], whereas enjoyment in helping others derives from the concept of altruism [25]. For this reason, the following hypothesis is presented:

Hypothesis 1. Intrinsic motivation positively affects the attitude towards knowledge sharing.

\subsection{Extrinsic motivation}

The extrinsic motivation contrasts with the intrinsic motivation, since its fundamental goal is to receive organisational rewards or reciprocal benefits [25]. As suggested by Deci and Ryan [46], extrinsic motivation 'refers to behavior where the reason for doing it is something other than an interest in the activity itself'. Although extrinsic motivation is considered to be a pale and impoverished form of motivation [45], many extrinsically motivated attitudes and behaviours are important in the social world [46]. Organisational rewards are incentive systems, which can motivate individuals to share their knowledge $[49,50]$. However, monetary compensation is not the only incentive for extrinsically motivating an individual's behaviour or attitude; it also includes enhanced reputation, learning opportunities and career advancement [49]. 
Reciprocal behaviour in a HEI context can provide a sense of mutual collaboration, inspiring knowledge owners to improve their relationships with each other, which can ensure ongoing knowledge sharing [25]. Supposing that individuals believe they can receive rewards or reciprocal benefits by sharing knowledge, they will develop a more positive attitude towards knowledge sharing and the following hypothesis is proposed:

Hypothesis 2. Extrinsic motivation positively affects the attitude towards knowledge sharing.

\subsection{Networking}

Individuals do not work, learn or share knowledge in isolation [24]. According to Avram [51], networking consists of circles in which individuals interact and connect with others. That networking is supposed to enhance knowledge sharing [52] and affect the extent of knowledge sharing [53], constituting an essential context in making knowledge sharing efficient and effective [51]. Nahapiet and Ghoshal [54] suggest that members of HEIs have recognised the important role of networking in promoting early access to new knowledge, facilitating its sharing and development, which often accelerates the advancement of science. According to Cormican and Dooley [55], knowledge sharing depends on personal networks and the willingness of individuals to participate in the process. Riege [56] considers the lack of networking to be one of the barriers of knowledge sharing. Therefore, the following hypothesis is proposed:

Hypothesis 3. Networking positively affects the attitude towards knowledge sharing.

\subsection{Attitude towards knowledge sharing}

According to Fishbein and Ajzen [42], attitude is a 'learned predisposition to respond in a consistently favorable or unfavorable manner with respect to a given object'. The TRA theory [42] has been used to investigate the influence of attitude towards knowledge sharing. Studies have shown that a positive attitude leads to a positive intention to share knowledge [57]. Wang and Noe [24] cite that individuals with a higher level of education and longer work experience are more probably to have positive attitudes towards knowledge sharing. Fullwood et al. [3] identify that in general, members of HEIs have positive attitudes and intentions towards knowledge sharing. This leads to the formulation of the following hypothesis:

Hypothesis 4. Attitude towards knowledge sharing positively affects the knowledge sharing intention.

\subsection{Organisational support}

Jolaee et al. [26] suggest that organisational support is 'one of the important concepts in management literature', the lack of which being one of the main barriers in the knowledge-sharing initiatives [58,59]. Some authors $[60,61]$ highlight that organisational support significantly influences knowledge sharing more than trust. The concept has recently been discussed more in HEIs, which has resulted in an increased provision of organisational support for knowledge sharing [16]. In this study, organisational support is comprised of technologies, processes and endorsement for the creation of informal networks. The following proposed hypothesis is based on the findings of the study of Igbaria et al. [62], which confirm the importance of organisational support in influencing the subjective norm:

Hypothesis 5. Organisational support positively affects subjective norm.

\subsection{Subjective norm}

The TRA theory posits that a person's intention is in turn a function of his or her attitude towards performing an action and of his or her subjective norm [44,63]. According to Fishbein and Ajzen's [42] definition, subjective norm 'is the person's perception that most people who are important to him or her think he or she should or should not perform the behavior in question'. Several empirical studies have found evidence that besides the attitude towards knowledge sharing, subjective norm positively impact the knowledge-sharing intention $[4,57,61,64]$. Therefore, it is expected that the subjective norm concerning the knowledge-sharing intention affects professors' and researchers' intentions towards knowledge sharing [65]. The following hypothesis is proposed:

Hypothesis 6. Subjective norm positively affects knowledge-sharing intention. 


\subsection{Trust}

In this study, trust refers to a person's reliance on sharing educational knowledge and scientific knowledge with others from the same institution or other institutions. Currall and Inkpen [66] define trust as 'the decision to rely on another party (i.e. person, group or organisation) under a condition of risk'. Due to this condition, the development of trust is often slow and incremental [66], which could turn into an important barrier to overcome when it comes to knowledge sharing [55]. Trust is an integral part of the knowledge-sharing process [40], and this process promotes the creation of new theories and ideas, and the establishment of new research principles [31]. The lack of trust, in terms of knowledge sharing among members of HEIs, can make this cross-fertilisation difficult. Kuo [67] believes that trust in the workplace also encourages knowledge sharing, such as collaborative behaviours. Previous study results show that trust affects knowledge sharing in HEIs $[10,40,68]$. Therefore, the following hypothesis is proposed:

Hypothesis 7. Trust positively affects the relationship with knowledge-sharing intention.

\subsection{Internal and external collaboration}

According to Tian et al. [38], collaboration and teamwork are not usually a concern in the context of HEIs. Probably due to the cult of the individual expert and self-motivation [30], members of HEIs prioritise self-study as the principal knowledge source [5], making collaboration secondary [38]. Gray [34] claims that 'the opportunity for collaborating arises because parties recognize the potential advantages of working together'. The literature also suggests that knowledge sharing has a particular influence in building and boosting collaboration within internal and external relationships $[10,69,70]$.

Internal collaboration occurs when members of an institution come together to solve problems or create innovations. Specifically, in the context of HEIs, knowledge sharing supports and strengthens collaboration among their members [10]. Furthermore, collaboration promotes intense interaction among members of an institution, allowing for the resolution of issues or the discussion of common work tasks [10], improving the performance of these members and contributing to the institution's success [29]. Thus, it is hypothesised as follows:

Hypothesis 8. Knowledge sharing intention positively affects the internal collaboration behaviour.

On the contrary, through external collaboration with other organisations, HEIs can find ways to have access to resources and expertise that they would not have originally [71], and to get support for their research activities, especially in recent years, due to cuts in government funding for research. The following hypothesis is proposed:

Hypothesis 9. Knowledge-sharing intention positively affects the external collaboration behaviour.

Table 1 shows a summary of the hypotheses proposed in the study.

\section{Materials and methods}

\section{I. Method used}

In general, applied PLS structural equation modelling (PLS-SEM) studies should provide information on the conceptual model, including a description of the inner and outer models, as well as the measurement modes, and the statistical results

Table I. Hypotheses.

Summary of the hypotheses

HI. Intrinsic motivation positively affects attitude towards knowledge sharing

$H 2$. Extrinsic motivation positively affects attitude towards knowledge sharing

H3. Networking positively affects attitude towards knowledge sharing

$\mathrm{H} 4$. Attitude towards knowledge sharing positively affects knowledge-sharing intention

H5. Organisational support positively affects subjective norm

H6. Subjective norm positively affects knowledge-sharing intention

H7. Trust positively affects relationship with knowledge-sharing intention

H8. Knowledge-sharing intention positively affects internal collaborative behaviour

H9. Knowledge-sharing intention positively affects external collaborative behaviour 
to support the subsequent interpretations and conclusions [72]. In addition, authors should report specific technicalities related to the software and the computational options used, as well as the parameter settings of complementary analysis procedures.

The PLS approach is appropriate for exploratory researches where theoretical knowledge is relatively scarce and a new theory needs to be developed [72,73], and it is well suited to handling complex models incorporating both reflective constructs and formative constructs [74]. The assessment of a PLS path model encompasses two stages [72]. The first stage, the measurement model, focuses on the analysis of each construct, and in a second stage, the structural model is assessed in order to test the hypotheses underlying the proposed conceptual model [75].

The model proposed in this research includes both reflective and formative constructs. All first-order constructs are reflective, while the second-order constructs (containing two layers of constructs that, in this study, correspond to trust and knowledge-sharing intention) are formative. The assessment of the measurement model will thus comprise the evaluation of reflective constructs and, subsequently, the evaluation of formative constructs. A first-order measurement model is one in which covariance between constructs is explained by a single latent variable relationship, whereas a second-order measurement model contains two levels of latent variables. In other words, the measurement model is designed to theoretically indicate the effect caused by the second-order construct on the first-order constructs, which in turn causes the measured variables [74].

According to Hair et al. [74], 'reflective indicators can be viewed as a representative sample of all the possible items available within the conceptual domain of the construct'. Various authors [76,77] suggest that the assessment of reflective constructs is carried out by analysing the reliability of the multiple-item scales, the convergent validity and the discriminant validity. In contrast to reflective constructs, formative constructs are the indicators that cause or form the construct, and are interchangeable among themselves [74,77].

This study applied PLS-SEM, using the SmartPLS 3 software $[77,78]$ to analyse the data with the application of a bootstrapping technique for significance testing [73].

\subsection{Data collection}

The study has been performed in the form of an online self-administered questionnaire from March to April 2017. A link to a survey platform was made available through e-mail. As the respondents were dispersed throughout different departments, schools and research units, the online survey was practical and convenient as a method of data collection. The questionnaires were administered anonymously to ensure confidentiality and the confidence of the respondents, preceded by a preliminary introduction that explained the objectives of the study.

The questionnaire was divided into two sections. The first section covered a set of questions eliciting the demographic characteristics of the respondents. The second section was comprised of a set of questions with items adapted from previous studies in the context of knowledge sharing [25-27,29,57,78]. This set of questions had the objective to measure, through the opinion of each respondent, the following constructs: intrinsic motivation, extrinsic motivation, networking, attitude towards knowledge sharing, organisational support, subjective norm, trust, knowledge-sharing intention, internal collaborative behaviour and external collaborative behaviour (see first column of Table 2). The response options for these items were presented to respondents on a five-point Likert-type scale, generally used to measure attitudes [79], where ' 1 ' corresponded to the least favourable level 'not agree at all', and ' 5 ' corresponded to the most favourable level 'fully agree'. The option 'do not know/do not answer' was also available for all questions.

The questionnaire was submitted to a pretest before the launch. According to Adams et al. [80], 'this is done to ensure that the questionnaire is clear to respondents and can be completed in the way you wish'. The pretest was conducted on a small scale by a panel of six professors/researchers. At the same time, they were requested to evaluate some questionnaire issues. No major problems were reported that would require a major revision of the questionnaire. The comments received in the evaluation process focused on the re-writing of some questions in order to clarify them. Subsequently, alterations were made in accordance with the comments, thus improving the questionnaire's understanding.

\subsection{Sample}

The population for this study consists of professors and researchers from a public HEI in Portugal. This HEI (created in 1973) quickly became one of the most dynamic and innovative universities in Portugal. This institution is ranked among the 100 best institutions of higher education in the world under 50 years old, for the sixth time in a row (2017), in the Times Higher Education ranking. It is the only one out of the youngest Portuguese HEIs to be integrated into the world's top 100. It is one of the six largest institutions in Portugal, with the highest concentration in a single campus, and it is organised into departments through a matrix structure. This institution is organised into 16 different departments, four 
Table 2. Demographic Profile of Respondents.

\begin{tabular}{|c|c|c|}
\hline & \multicolumn{2}{|l|}{ Frequency } \\
\hline & Absolute & Relative (\%) \\
\hline \multicolumn{3}{|l|}{ Gender } \\
\hline Female & 89 & 50.6 \\
\hline Male & 87 & 49.4 \\
\hline \multicolumn{3}{|l|}{ Age } \\
\hline$<30$ years & 6 & 3.4 \\
\hline $30-40$ years & 31 & 17.6 \\
\hline $4 I-50$ years & 74 & 42.0 \\
\hline $51-60$ years & 51 & 29.0 \\
\hline$>60$ years & 14 & 8.0 \\
\hline \multicolumn{3}{|l|}{ Level of education } \\
\hline Aggregation & 23 & 13.1 \\
\hline $\mathrm{PhD}$ & 121 & 68.8 \\
\hline Masters & 22 & 12.5 \\
\hline Degree & 10 & 5.7 \\
\hline \multicolumn{3}{|l|}{ Position in department } \\
\hline Full professor & II & 6.3 \\
\hline Associate professor & 28 & 15.9 \\
\hline Assistant professor & 89 & 50.6 \\
\hline Lecturer & 21 & 11.9 \\
\hline Researcher & 19 & 10.8 \\
\hline Others & 8 & 4.5 \\
\hline \multicolumn{3}{|l|}{ Dedication } \\
\hline Integral & 139 & 79.0 \\
\hline Partial & 37 & 21.0 \\
\hline \multicolumn{3}{|l|}{ Scientific area } \\
\hline Life and health & 17 & 9.7 \\
\hline Natural and environment & 18 & 10.2 \\
\hline Science and engineering & 58 & 33.0 \\
\hline Social and humanities & 83 & 47.2 \\
\hline \multicolumn{3}{|c|}{ Years of service in current institution } \\
\hline$<$ I year & 15 & 8.5 \\
\hline $\mathrm{I}-5$ years & 15 & 8.5 \\
\hline $6-10$ years & 29 & 16.5 \\
\hline $1 \mathrm{I}-20$ years & 63 & 35.8 \\
\hline$>20$ years & 54 & 30.7 \\
\hline \multicolumn{3}{|c|}{ Years of experience as professor } \\
\hline I year & 8 & 4.5 \\
\hline $\mathrm{I}-5$ years & 13 & 7.4 \\
\hline $6-10$ years & 22 & 12.5 \\
\hline I I-20 years & 52 & 29.5 \\
\hline$>20$ years & 81 & 46.0 \\
\hline \multicolumn{3}{|c|}{ Years of experience as researcher } \\
\hline$<$ I year & 10 & 5.7 \\
\hline $\mathrm{I}-5$ years & 8 & 4.5 \\
\hline $6-10$ years & 34 & 19.3 \\
\hline $1 \mathrm{I}-20$ years & 51 & 29.0 \\
\hline$>20$ years & 73 & 41.5 \\
\hline \multicolumn{3}{|c|}{ In an average year, how many conferences do you participate? } \\
\hline 0 & II & 6.3 \\
\hline $1-3$ & 126 & 71.6 \\
\hline $4-6$ & 29 & 16.5 \\
\hline $7-10$ & 5 & 2.8 \\
\hline $11-20$ & 2 & 1.1 \\
\hline $21-30$ & 2 & I.I \\
\hline$>30$ & 1 & 0.6 \\
\hline \multicolumn{3}{|c|}{ In an average year, how many scientific papers do you publish? } \\
\hline 0 & 12 & 6.8 \\
\hline $1-3$ & 103 & 58.5 \\
\hline
\end{tabular}


Table 2. (continued)

\begin{tabular}{llr}
\hline & Frequency & Relative (\%) \\
\cline { 2 - 3 } & Absolute & 23.3 \\
$4-6$ & 41 & 6.8 \\
$7-10$ & 12 & 2.3 \\
$11-20$ & 4 & 1.7 \\
$21-30$ & 3 & 0.6 \\
$>30$ & 1 & \\
$n=176$ & & \\
\hline
\end{tabular}

polytechnic schools, and 18 research centres, according to a wide range of fields. It has about 15,000 students on undergraduate and postgraduate programmes, and over 1000 professors and researchers.

A total of 1020 professors and researchers were contacted through e-mail and requested to fill out the questionnaire. In total, 297 (29.1\%) questionnaires returned, with 121 having been eliminated due to incomplete data. As a result, 176 (17.3\%) valid answers from four scientific areas (i.e. life and health, natural and environment, science and engineering, and social and humanities) were used in the data analysis. The sample was gender balanced $(50.6 \%$ female and $49.4 \%$ male). In total, $75.5 \%$ of respondents had more than 10 years of professional experience and $66.5 \%$ had more than 10 years of affiliation with the institution. Table 2 presents the demographic profile characteristics of the respondents.

Although the PLS method is remarkably stable even at low sample sizes, sample size is a basic PLS method issue [73]. Based on Barclay et al. [81], several authors suggest using the ' 10 times rule', which specifies minimum sample size as 10 times the largest number of predictors for any dependent variable in the model. However, Hair et al. [73] emphasise the fact that 'this rule of thumb does not take into account effect size, reliability, the number of indicators, and other factors known to affect power and can thus be misleading'. This study used, as suggested by Hair et al. [74], the software $\mathrm{G}^{*}$ Power 3.1.9.2, a flexible statistical power analysis programme commonly used for social and behavioural research [82]. The procedure implies the identification of the largest number of predictors that a construct receives. In the proposed model, the most complex regression involves the number of structural paths directed at the attitude towards knowledge sharing and knowledge-sharing intention constructs, which are three. The parameters used to estimate the minimum sample size were those recommended by Hair et al. [74]: $80 \%$ of statistical power $(1-\beta)$, effect size median $\left(f^{2}\right)$ of 0.15 , and $5 \%$ probability of error $(\alpha)$. Thus, according to the results, the minimum sample size would be 77 , but to have a more consistent model, it is interesting to have at least twice the value [83]. As there were 176 valid responses collected, the PLS analysis seems to have sufficient power.

\section{Results and discussion}

\section{I. Reflective constructs}

The reliability of the constructs was analysed using composite reliability (CR), since it has been considered a more accurate measurement than Cronbach's alpha [84]. This measure is appropriate for constructs with reflective indicators. In Table 3, the values of CR of all constructs are shown to be higher than the reference value of $0.70[77,84]$, and furthermore, the results surpassed the value of 0.80 which Garson [77] suggests to be considered good for confirmatory research. Moreover, all of the indicators had factor loadings greater than the value of 0.60 as recommended in the literature by Henseler et al. [85].

The convergent validity is the degree to which multiple items used to measure the same concept are in agreement [74]. The convergent validity was evaluated through the average variance extracted (AVE). As presented in Table 3, all constructs have an AVE higher than 0.50, attesting to a good convergent validity of the scales used [72].

Discriminant validity assessment has become a generally accepted prerequisite for analysing relationships between latent variables. The Fornell-Larcker criterion and the examination of cross-loading are dominant approaches for evaluating discriminant validity [86]. However, Henseler et al. [86] show, by means of a simulation study, that these approaches have 'an unacceptably low sensitivity, which means that they are largely unable to detect a lack of discriminant validity' [86]. They demonstrate this approach's superior performance by means of a Monte Carlo simulation study, in which they compare the new approach with the Fornell-Larcker criterion and the assessment of cross-loadings. Following the recommendation of Henseler et al. [86], this study uses the Heterotrait-Monotrait (HTMT) ratio criterion to assess discriminant 
Table 3. Measurement Statistics of Construct Scales.

\begin{tabular}{|c|c|c|c|c|c|c|}
\hline Construct/indicators & Mean & SD & $\begin{array}{l}\text { Indicator } \\
\text { loadings }\end{array}$ & $t$-value ${ }^{\mathrm{a}}$ & $C R$ & AVE \\
\hline Intrinsic motivation & 4.440 & 0.551 & - & - & 0.878 & 0.645 \\
\hline $\begin{array}{l}\text { I am willing to share knowledge because I like to help my } \\
\text { colleagues }\end{array}$ & 4.448 & 0.721 & 0.657 & 9.411 & & \\
\hline $\begin{array}{l}\text { I think that sharing my knowledge would help in solving } \\
\text { colleagues' problems }\end{array}$ & 4.460 & 0.629 & 0.864 & 29.313 & & \\
\hline $\begin{array}{l}\text { I think that sharing my knowledge would create new } \\
\text { opportunities for my institution }\end{array}$ & 4.425 & 0.678 & 0.871 & 39.164 & & \\
\hline $\begin{array}{l}\text { I think that sharing my knowledge would help improve my } \\
\text { institution's performance }\end{array}$ & 4.425 & 0.735 & 0.803 & 13.598 & & \\
\hline Extrinsic motivation & 3.382 & 0.783 & - & - & 0.835 & 0.559 \\
\hline $\begin{array}{l}\text { I think that sharing my knowledge makes my colleagues better } \\
\text { aware of my skills }\end{array}$ & 4.080 & 0.928 & 0.698 & 9.348 & & \\
\hline $\begin{array}{l}\text { I consider that my institution recognises/values those who } \\
\text { share knowledge }\end{array}$ & 3.329 & 1.140 & 0.810 & 17.870 & & \\
\hline $\begin{array}{l}\text { I consider that my institution provides its members with a fair } \\
\text { evaluation/reward system for sharing knowledge }\end{array}$ & 2.849 & 1.026 & 0.791 & 13.469 & & \\
\hline $\begin{array}{l}\text { I think that sharing knowledge has a direct impact on the } \\
\text { progression of my career }\end{array}$ & 2.854 & 1.245 & 0.684 & 9.259 & & \\
\hline Networking & 3.628 & 0.771 & - & - & 0.851 & 0.659 \\
\hline $\begin{array}{l}\text { I interact frequently with colleagues from the institution in } \\
\text { sharing teaching and scientific knowledge }\end{array}$ & 3.710 & 0.992 & 0.875 & 42.198 & & \\
\hline $\begin{array}{l}\text { I maintain good networking with people from other } \\
\text { organisations in the context of knowledge sharing }\end{array}$ & 3.736 & 1.019 & 0.678 & 9.005 & & \\
\hline $\begin{array}{l}\text { I communicate with other members of my institution through } \\
\text { informal contacts in the context of knowledge sharing }\end{array}$ & 3.903 & 0.918 & 0.866 & 35.453 & & \\
\hline Attitude towards knowledge sharing & 4.310 & 0.595 & - & - & 0.890 & 0.731 \\
\hline $\begin{array}{l}\text { Sharing knowledge with my institution colleagues is important } \\
\text { to me }\end{array}$ & 4.193 & 0.783 & 0.903 & 59.954 & & \\
\hline $\begin{array}{l}\text { Sharing knowledge with my colleagues at the institution is an } \\
\text { experience that pleases me }\end{array}$ & 4.201 & 0.800 & 0.896 & 50.123 & & \\
\hline $\begin{array}{l}\text { I consider that the sharing of knowledge and experience } \\
\text { promotes the creation of new knowledge }\end{array}$ & 4.566 & 0.607 & 0.759 & $14.1 \mid 4$ & & \\
\hline Organisational support & 3.581 & 0.723 & - & - & 0.869 & 0.691 \\
\hline $\begin{array}{l}\text { My institution provides appropriate technologies to support } \\
\text { knowledge sharing (e.g. academic portal, website, e-mail) }\end{array}$ & 3.924 & 0.888 & 0.724 & 14.758 & & \\
\hline $\begin{array}{l}\text { My institution has appropriate mechanisms for knowledge } \\
\text { sharing (e.g. meeting, academic meeting) }\end{array}$ & 3.485 & 0.844 & 0.880 & 41.731 & & \\
\hline $\begin{array}{l}\text { My institution supports and encourages the creation of } \\
\text { informal mechanisms for knowledge sharing (e.g. communities of } \\
\text { practice, thematic meetings open to the community) }\end{array}$ & 3.333 & 0.877 & 0.880 & 43.248 & & \\
\hline Subjective norm & 3.842 & 0.669 & - & - & 0.904 & 0.704 \\
\hline $\begin{array}{l}\text { I feel that, considering the culture of my institution, I should } \\
\text { share my knowledge }\end{array}$ & 3.786 & 0.856 & 0.716 & 17.795 & & \\
\hline $\begin{array}{l}\text { People who influence my behaviour (e.g. colleagues and } \\
\text { friends) think that I should share my knowledge }\end{array}$ & 3.800 & 0.791 & 0.883 & 21.942 & & \\
\hline $\begin{array}{l}\text { People who are important to me (e.g. colleagues and friends) } \\
\text { think that I should share my knowledge }\end{array}$ & 3.844 & 0.771 & 0.895 & 38.115 & & \\
\hline $\begin{array}{l}\text { People whose opinion I value (e.g. colleagues and friends) think } \\
\text { that I should share my knowledge } \\
\text { Trust }\end{array}$ & 3.939 & 0.798 & 0.844 & 25.299 & & \\
\hline Educational knowledge & 4.062 & 0.678 & - & - & 0.806 & 0.581 \\
\hline $\begin{array}{l}\text { I do not mind sharing my teaching materials with colleagues in } \\
\text { my institution }\end{array}$ & 4.326 & 0.827 & 0.724 & 15.152 & & \\
\hline $\begin{array}{l}\text { When I face difficulties in teaching, I ask my colleagues from } \\
\text { my institution for help }\end{array}$ & 4.059 & 0.846 & 0.789 & 19.138 & & \\
\hline $\begin{array}{l}\text { I believe that by sharing knowledge with my colleagues in my } \\
\text { institution, they will respond in the same way }\end{array}$ & 3.800 & 0.989 & 0.777 & 22.929 & & \\
\hline Scientific knowledge & 3.924 & 0.773 & - & - & 0.843 & 0.849 \\
\hline
\end{tabular}


Table 3. (continued)

\begin{tabular}{|c|c|c|c|c|c|c|}
\hline Construct/indicators & Mean & SD & $\begin{array}{l}\text { Indicator } \\
\text { loadings }\end{array}$ & $t$-value ${ }^{a}$ & $C R$ & AVE \\
\hline $\begin{array}{l}\text { I do not mind announcing the results of my research to my } \\
\text { institution colleagues before I publish them }\end{array}$ & 3.953 & 1.084 & 0.743 & 17.118 & & \\
\hline $\begin{array}{l}\text { When I face difficulties in my investigations, I ask my colleagues } \\
\text { from my institution for help }\end{array}$ & 4.059 & 0.873 & 0.826 & 25.617 & & \\
\hline I believe that by sharing knowledge resulting of my & 3.759 & 0.945 & 0.832 & 31.120 & & \\
\hline $\begin{array}{l}\text { investigations with my colleagues they will respond in the same } \\
\text { way }\end{array}$ & & & & & & \\
\hline \multicolumn{7}{|l|}{ Knowledge share intention } \\
\hline Educational knowledge & 3.990 & 0.720 & - & - & 0.919 & 0.695 \\
\hline $\begin{array}{l}\text { I intend to share the tacit knowledge and know-how gained in } \\
\text { teaching with my institution colleagues in the future }\end{array}$ & 4.183 & 0.719 & 0.807 & 23.521 & & \\
\hline $\begin{array}{l}\text { I intend to share teaching materials developed by me with my } \\
\text { institution colleagues in the future }\end{array}$ & 4.152 & 0.818 & 0.837 & 39.955 & & \\
\hline $\begin{array}{l}\text { I intend to share the tacit knowledge and know-how gained in } \\
\text { teaching with colleagues from other institutions in the future }\end{array}$ & 3.893 & 0.898 & 0.903 & 62.853 & & \\
\hline $\begin{array}{l}\text { I intend to share teaching materials developed by me with } \\
\text { colleagues from other institutions in the future }\end{array}$ & 3.694 & 1.031 & 0.873 & 54.372 & & \\
\hline $\begin{array}{l}\text { I intend to participate in group discussions, workshops, and } \\
\text { communities of practice to share knowledge in the future }\end{array}$ & 4.031 & 0.838 & 0.744 & 18.945 & & \\
\hline Scientific knowledge & 4.160 & 0.716 & - & - & 0.918 & 0.849 \\
\hline $\begin{array}{l}\text { I intend to share knowledge and know-how gained in research } \\
\text { with my institution colleagues in the future }\end{array}$ & 4.189 & 0.740 & 0.921 & 49.267 & & \\
\hline $\begin{array}{l}\text { I intend to share knowledge and know-how gained in research } \\
\text { with colleagues from other institutions in the future }\end{array}$ & 4.130 & $0.81 \mathrm{I}$ & 0.924 & 50.407 & & \\
\hline Internal collaborative behaviour & 3.810 & 0.584 & - & - & 0.880 & 0.787 \\
\hline $\begin{array}{l}\text { Regarding teaching, I prefer to work in group rather than } \\
\text { work alone }\end{array}$ & 3.830 & 0.962 & 0.908 & 47.077 & & \\
\hline $\begin{array}{l}\text { Regarding investigation, I prefer to work in group rather than } \\
\text { work alone }\end{array}$ & 4.227 & 0.829 & 0.866 & 23.960 & & \\
\hline External collaborative behaviour & 3.475 & 0.569 & - & - & 0.800 & 0.573 \\
\hline $\begin{array}{l}\text { I believe that collaborative relationships with others higher } \\
\text { education institutions promote the sharing of knowledge and } \\
\text { recognition of my work }\end{array}$ & 4.036 & 0.887 & 0.805 & II.058 & & \\
\hline $\begin{array}{l}\text { I believe that collaborative relationships with non-academic } \\
\text { organisations promote the sharing of knowledge and recognition } \\
\text { of my work }\end{array}$ & 3.788 & 0.979 & 0.766 & 9.364 & & \\
\hline $\begin{array}{l}\text { My institution promotes and recognises collaborative } \\
\text { relationships with non-academic organisations }\end{array}$ & 3.444 & 0.972 & 0.677 & 6.072 & & \\
\hline
\end{tabular}

AVE, average variance extracted; $C R$, composite reliability.

${ }^{a} T$-values were obtained with the bootstrapping procedure (5000 samples) and are significant at the $0.00 \mathrm{I}$ level (two-tailed test).

validity (Table 4). According to these authors, since the HTMT value is clearly below 0.90 , discriminant validity has been well established between the reflective constructs.

\subsection{Formative constructs}

The second-order constructs included in the conceptual model proposed (Figure 1) - trust and knowledge-sharing intention - were analysed. After testing the quality of the first-order constructs, and ensuring that all requirements are met [74], the assessment of the quality of second-order constructs is comprised of two stages. The multicollinearity among the first-order constructs is examined, as well as the weights and significance level of the first-order constructs on the second-order constructs [77]. The multicollinearity was analysed through the variance inflation factor (VIF), with values varying between 1.31 and a maximum of 1.95 , which is far below the common cut-off threshold of 5 [73].

Values of outer weights represent the relative contribution to the construct, or its relative importance. Their values vary from 0 to an absolute maximum lower than 1 [77]. The further the value is different from zero, the more a formative indicator truly contributes to forming the construct [74]. As shown in Table 5, all first-order constructs are higher than 0 , 
Table 4. Discriminant Validity of the Constructs - HTMT Results.

\begin{tabular}{|c|c|c|c|c|c|c|c|c|c|c|}
\hline Constructs & I & 2 & 3 & 4 & 5 & 6 & 7 & 8 & 9 & 10 \\
\hline I. Intrinsic motivation & 1.00 & & & & & & & & & \\
\hline 2. Extrinsic motivation & 0.47 & 1.00 & & & & & & & & \\
\hline 3. Networking & 0.51 & 0.35 & 1.00 & & & & & & & \\
\hline 4. Attitude towards knowledge sharing & 0.66 & 0.41 & 0.58 & 1.00 & & & & & & \\
\hline 5. Organisational support & 0.36 & 0.46 & 0.41 & 0.34 & 1.00 & & & & & \\
\hline 6. Subjective norm & 0.54 & 0.49 & 0.54 & 0.55 & 0.56 & 1.00 & & & & \\
\hline 7. Trust & 0.38 & 0.29 & 0.43 & 0.48 & 0.22 & 0.35 & 1.00 & & & \\
\hline 8. Knowledge-sharing intention & 0.46 & 0.31 & 0.53 & 0.60 & 0.23 & 0.46 & 0.67 & 1.00 & & \\
\hline 9. Internal collaborative behaviour & 0.33 & 0.27 & 0.46 & 0.53 & 0.26 & 0.37 & 0.40 & 0.47 & 1.00 & \\
\hline 10. External collaborative behaviour & 0.39 & 0.35 & 0.41 & 0.47 & 0.38 & 0.44 & 0.36 & 0.32 & 0.37 & 1.00 \\
\hline
\end{tabular}

HTMT, Heterotrait-Monotrait.

Table 5. Weights of the First-Order Constructs on the Second-Order Constructs.

\begin{tabular}{lllr}
\hline Second-order constructs & First-order constructs & Weight & $t$-value \\
\hline Trust & Educational knowledge & 0.543 & $19.585^{* * * *}$ \\
Knowledge-sharing intention & Scientific knowledge & 0.567 & $23.949 * * *$ \\
& Educational knowledge & 0.771 & $43.168^{* * *}$ \\
& Scientific knowledge & 0.316 & $20.974 * * *$ \\
\hline
\end{tabular}

$* * * p<0.001$ based on 5000 bootstraps.

which means that they positively contribute to the second-order constructs. Educational and scientific knowledge contribute almost with the same intensity as the first-order constructs to the formative construct of trust. In contrast to Kim and Ju's [29] study conducted through questionnaires administered to 109 faculty members at a private university in South Korea that analyzes major factors for knowledge sharing among faculty members, educational knowledge emerges as the first-order construct with more weight on the knowledge-sharing intention. As stressed by these authors, although some of these materials have high scholarly value as well as practical know-how, they are not shared among colleagues being instead organised and preserved by each individual member.

\subsection{Structural model assessment}

Following the assessment of the measurement model, the results of the structural model are depicted in Figure 2. In this study, predictive power and the relationships between the constructs of both the models were examined. To evaluate the predictive power of the research model, the coefficient of determination $\left(R^{2}\right)$ and Stone-Geisser's $Q^{2}$ technique were used. This is due to the $R^{2}$ of the endogenous latent variables being the essential criterion for the assessment, and StoneGeisser's $Q^{2}$ being the predominant measure of predictive relevance [85].

Findings presented in Figure 2 reveal that the model has a reasonable prediction power, since the $R^{2}$ values vary between 0.103 and 0.562 and the predictive relevance $Q^{2}$ values range from 0.096 to 0.544 , showing the predictive importance of endogenous constructs [72]. The constructs with higher variance explained by the model were the knowledge-sharing intention and attitude towards knowledge sharing $\left(R^{2}=0.562\right.$ and 0.519 , respectively) followed by the subjective norm $\left(R^{2}=0.316\right)$. On the contrary, the constructs with lower variance explained were internal collaborative behaviour and external collaborative behaviour $(21.7 \%$ and $10.3 \%$, respectively).

Table 6 summarises the results of the hypotheses testing and provides evidence that only one hypothesis is not supported.

The first three hypotheses proposed that intrinsic motivation $(\mathrm{H} 1)$, extrinsic motivation $(\mathrm{H} 2)$ and networking $(\mathrm{H} 3)$ positively affect attitude towards knowledge sharing. Results shown that only $\mathrm{H} 1(\beta=0.456, p<0.001)$ and $\mathrm{H} 3$ ( $\beta=0.321, p<0.001)$ had a significant and positive influence on attitude towards knowledge sharing, while hypothesis $\mathrm{H} 2(\beta=0.079, p>0.05)$ was not supported. 


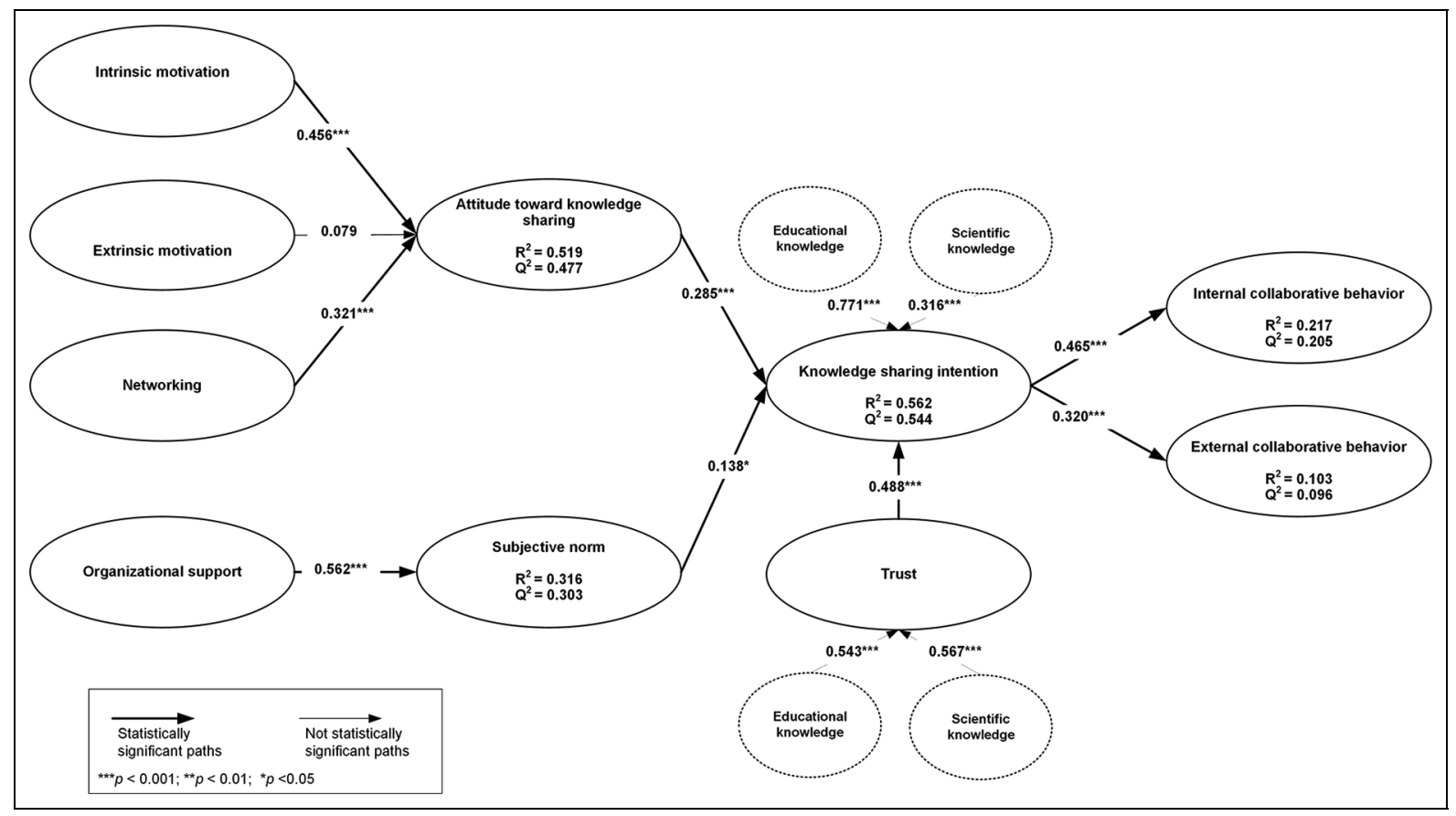

Figure 2. Results of structural model.

Table 6. Hypotheses Testing.

\begin{tabular}{lr}
\hline Path & Result \\
\hline HI. Intrinsic motivation $\rightarrow$ attitude towards knowledge sharing & Supported \\
H2. Extrinsic motivation $\rightarrow$ attitude towards knowledge sharing & Not supported \\
H3. Networking $\rightarrow$ attitude towards knowledge sharing & Supported \\
H4. Attitude towards knowledge sharing $\rightarrow$ knowledge-sharing intention & Supported \\
H5. Organisational support $\rightarrow$ subjective norm & Supported \\
H6: Subjective norm $\rightarrow$ knowledge-sharing intention & Supported \\
H7. Trust $\rightarrow$ knowledge-sharing intention & Supported \\
H8. Knowledge-sharing intention $\rightarrow$ internal collaborative behaviour & Supported \\
H9. Knowledge-sharing intention $\rightarrow$ external collaborative behaviour & Supported \\
\hline
\end{tabular}

As expected, given that members of HEIs are used to have some freedom and autonomy [87] and intrinsic motivation is an activity moved by self-determination, and is free of external incentives, pressures, or rewards [45], this factor was the one that most positively affects the knowledge-share attitude. Consequently, consistent with the concept of extrinsic motivation as a controlled motivation, this factor was not considered as one that affects attitude towards knowledge sharing. Networking was the other factor that affects attitude in this institution. Networking refers to the extent of individuals' contact with other people. Knowledge is dynamic and members of HEIs are critical actors involved in the creation and dissemination of knowledge. This form of interaction assumes an important role, since it is not just an activity related to knowledge sharing but also about leverage of knowledge, as suggested by Riege [56] in his article that reviews and discusses potential knowledge-sharing barriers.

As proposed in the hypothesis $\mathrm{H} 4$, the result showed that professors' and researches' attitudes towards knowledge sharing affect their knowledge-sharing intention $(\beta=0.285, p<0.001)$. This finding is consistent with that of Lin [25], who studied knowledge-sharing intentions of 172 employees from 50 large organisations in Taiwan. Bock et al. [57] also identified, in their study with 154 managers from 27 Korean organisations, that the intention to share knowledge is greater when the attitude towards knowledge sharing is more favourable.

Organisational support (H5) $(\beta=0.562, p<0.05)$ presented a strong influence on subjective norm towards the knowledge-sharing intention. This result is consistent with that found in the work of Jolaee et al. [26], which tested this 
hypothesis through a survey of academic staff of three Social Sciences faculties at one university in Malaysia. However, for H6 ( $\beta=0.138, p<0.05)$, the results indicated that, in this study, knowledge-sharing intention was not affected so strongly by the subjective norm. This result could be explained by the fact that professors and researchers are fully aware of knowledge sharing and its related benefit for themselves, and that they prefer to go through the decision-making process with less interventions from colleagues and peer groups when it comes to knowledge-sharing intention. This finding is similar to that found in Jolaee et al. [26]. However, it is different from that found in the work of Bock et al. [57], which suggests that subjective norms can influence intentions, especially within groups with strong collectivist orientation like Korean organisations.

In the context of this study, trust was defined as the degree of relying on sharing educational and scientific knowledge with colleagues. The result strongly supported the hypothesis $\mathrm{H} 7(\beta=0.488, p<0.001)$, meaning that trust had a positive effect on the intention of knowledge sharing. This finding is similar to those found in previous studies within HEIs. Tan [10] conducted a survey in five universities in Malaysia and identified that trust has a significant and positive influence on knowledge sharing, suggesting that HEIs should create and reinforce an environment of trust among their faculty members. The study of Patel and Ragsdell [40], in two faculties at a British university, also concludes that trust plays an integral part in the knowledge-sharing process within organisations. However, current business models with geographically dispersed companies and ongoing partnership and restructuring actions, as well as the increasing tendency to replace face-to-face communication with digital communication, constitute a challenge for the development of trust in relationships. In the opinion of Cook et al. [88], trust is no longer the central pillar of the social order and may not even be considered very important in most processes of knowledge sharing and collaboration that are managed quite effectively.

Finally, hypotheses $\mathrm{H} 8$ and $\mathrm{H} 9$ proposed that the knowledge-sharing intention has a positive relationship with the collaboration behaviour within the institution and with other organisations, respectively. Results confirmed that $\mathrm{H} 8$ $(\beta=0.465, p<0.001)$ and $\mathrm{H} 9(\beta=0.320, p<0.001)$ are strongly impacted by knowledge-sharing intention.

\section{Conclusion and future work}

\section{I. Conclusion}

This study proposed that knowledge-sharing intention affects the collaborative behaviour among professors and researchers positively in the specific context of a public Portuguese HEI. In order to reach this main objective, the conceptual research model was developed based on the TRA theory. This study applied PLS-SEM to analyse the data with the application of a bootstrapping technique for significance testing. First, the individual factors (i.e. intrinsic motivation, extrinsic motivation and networking) that could positively affect the attitude towards knowledge sharing were examined and analysed, followed by how attitude towards knowledge sharing, subjective norm and trust affect the knowledge-sharing intention, and finally, how the latter affects internal and external collaborative behaviour.

The results indicated that intrinsic motivation and networking were the factors that positively affected the attitude towards knowledge sharing, while extrinsic motivation did not influence it. It is believed that HEIs and their members should establish mechanisms based on the intrinsic motivation and the networking in order to promote and encourage knowledge sharing.

The analysis of results also allowed for the identification of trust as the variable that more strongly affects the knowledge-sharing intention, which is in accordance with other studies reported in the literature.

Finally, the study identified that knowledge-sharing intention has a positive influence in collaborative behaviour, with this influence being stronger in the case of internal rather than external collaborative behaviour.

\subsection{Scientific and managerial implications}

The literature suggests that this theme is quite relevant and that there is an evident lack of empirical studies that properly investigate the relationship between knowledge-sharing and collaborative behaviour in HEIs. In a scientific perspective, this study contributed to the advancement of knowledge in the area, specifically based on empirical results, since previous studies based on empirical data mostly focused on business organisations or non-European HEIs, with only few ones have been conducted in Europe, and in particular in Portuguese HEIs.

In a managerial perspective, this work contributes to the identification of relevant facts related to the knowledge sharing in the context of a Portuguese HEI. The results obtained can support the institution's management in the strategies definition and development of future actions, in order to promote an organisational culture based on knowledge management that significantly leads to knowledge sharing and collaboration relationships. 
Ryan and Deci [45] argue that the factors in social contexts, such as interpersonal events and structures that conduce towards feelings of competence during action, can enhance intrinsic motivation because they allow satisfaction of the basic psychological need for competence. In addition, several studies in the literature observe that people, when exposed to intrinsically motivated others, are more probably to behave in similar ways. Thus, considering that the results of this study show that members of this HEI prioritise the intrinsic motivation, it is possible to suggest that the institution should establish mechanisms favourable for effective knowledge sharing such as the following:

- Encouraging members to share knowledge by organising open discussions, forums, seminars or colloquiums, or applying communities of practice with the aim to create a collaborative sharing environment among members with a common scientific interest;

- Making the individuals' sharing activities and knowledge contributions more visible to the remaining of the institution can enhance intrinsic motivation and so encourages knowledge-sharing and collaborative behaviour.

\subsection{Limitations and future research}

Since the data collection was restricted to one Portuguese public HEI, the conclusions cannot be extended to other institutions, thus making it impossible to generalise the obtained conclusions.

Considering the limitation of the study and that the literature review showed that most of the studies focused on a single HEI or a single country, future researches should apply this study to other Portuguese HEIs in order to obtain more data and better characterise Portuguese HEIs' knowledge-sharing and collaboration behaviour. Then, it will be interesting to compare our results with the ones from HEIs from other countries and cultures.

Particularly in the HEI where the study was conducted, it is intended, as future work, to study the demographic variables influence on the knowledge-sharing behaviour, as well as analysing and characterising the knowledge-sharing and collaboration practices among researchers and/or teachers at this institution will also be important.

\section{Acknowledgments}

This work was supported by Fundação para a Ciência e a Tecnologia (FCT), through CIDMA within project UID/MAT/04106/2019 and through IEETA in the context of the project UID/CEC/00127/2019.

\section{Declaration of conflicting interests}

The author(s) declared no potential conflicts of interest with respect to the research, authorship, and/or publication of this article.

\section{Funding}

The author(s) received no financial support for the research, authorship, and/or publication of this article.

\section{ORCID iD}

Marcello Chedid (iD) https://orcid.org/0000-0003-0435-6568

\section{References}

[1] Howell KE and Annansingh F. Knowledge generation and sharing in UK universities: a tale of two cultures? Int J Inf Manage 2013; 33(1): 32-39.

[2] Ali OF, Gohneim A, Roubaie A et al. Knowledge sharing culture in higher education institutions: critical literature review. In: Proceedings of the European, Mediterranean \& Middle Eastern conference on information systems, 2014, pp. 1-18, https:// www.researchgate.net/publication/267512109_Knowledge_Sharing_Culture_in_Higher_Education_Institutions_Critical_Literature_ Review_1_Knowledge_Sharing_Culture_in_Higher_Education_Institutions_Critical_Literature_Review

[3] Fullwood R, Rowley J and Delbridge R. Knowledge sharing amongst academics in UK universities. J Knowl Manag 2013; 17(1): 123-136.

[4] Ramayah T, Yeap JAL and Ignatius J. An empirical inquiry on knowledge sharing among academicians in higher learning institutions. Minerva 2013; 51(2): 131-154.

[5] Tian J, Nakamori Y and Wierzbicki AP. Knowledge management and knowledge creation in academia: a study based on surveys in a Japanese research university. J Knowl Manag 2009; 13(2): 76-92.

[6] Tippins MJ. Implementing knowledge management in academia: teaching the teachers. Int J Educ Manag 2003; 17(7): 339 345. 
[7] Rowley J. Is higher education ready for knowledge management? Int J Educ Manag 2000; 14(7): 325-333.

[8] Nissen HA, Evald MR and Clarke AH. Knowledge sharing in heterogeneous teams through collaboration and cooperation: exemplified through public-private-innovation partnerships. Ind Mark Manag 2014; 43(3): 473-482.

[9] Epure M. Knowledge management - capturing, distributing and effectively use of knowledge. Ann Acad Rom Sci New Ser Econ Law Sociol 2016; 2(2): 5-18.

[10] Tan CNL. Enhancing knowledge sharing and research collaboration among academics: the role of knowledge management. $J$ Higher Educ 2016; 71(4): 525-556.

[11] Kauppila O, Mursula A, Harkonen J et al. Evaluating university-industry collaboration: the European foundation of quality management excellence model-based evaluation of university-industry collaboration. Tert Educ Manag 2015; 21(3): 229-244.

[12] Mendes L, Nunes A and Sequeira T. Influence of human capital on firms' and nations' performance. A bi-disciplinary literature review. Argument Oeconom 2012; 29(2): 5-32.

[13] Desouza KC. Barriers to effective use of knowledge management systems in software engineering. Commun ACM 2003; 46(1): 99-101.

[14] Walz DB, Elam JJ and Curtis B. Inside a software design team: knowledge acquisition, sharing, and integration. Commun ACM 1993; 36(10): 63-77.

[15] Lee YS. The sustainability of university-industry research collaboration: an empirical assessment. J Technol Transf 2000; 25(2): 111-133.

[16] Freitas IMB, Geuna A and Rossi F. Finding the right partners: institutional and personal modes of governance of universityindustry interactions. Res Policy 2013; 42(1): 50-62.

[17] Cohen WM, Nelson RR and Walsh JP. Links and impacts: the influence of public research on industrial R\&D. Manage Sci 2002; 48(1): 1-23.

[18] Mansfield E and Lee JY. The modern university: contributor to industrial innovation and recipient of industrial R\&D support. Res Policy 1996; 25: 1047-1058.

[19] Melin G. Pragmatism and self-organization: research collaboration on the individual level. Res Policy 2000; 29(1): 31-40.

[20] Weber RO, Morelli ML, Atwood ME et al. Designing a knowledge management approach for the CAMRA community of science. In: Proceedings of the 6th international conference on PAKM 2006, Vienna, 30 November-1 December 2006, pp. 315325. Berlin: Springer-Verlag, 2006.

[21] Sadiq Sohail M and Daud S. Knowledge sharing in higher education institutions: perspectives from Malaysia. VINE 2009; 39(2): 125-142.

[22] Tohidinia Z and Mosakhani M. Knowledge sharing behaviour and its predictors. Ind Manag Data Syst 2010; $110(4)$ : 611-631.

[23] Al-Kurdi O, El-Haddadeh R and Eldabi T. Knowledge sharing in higher education institutions: a systematic review. $J$ Enterp Inf Manag 2018; 31(2): 226-246.

[24] Wang S and Noe RA. Knowledge sharing: a review and directions for future research. Hum Resour Manag Rev 2010; 20(2): 115-131.

[25] Lin HF. Effects of extrinsic and intrinsic motivation on employee knowledge sharing intentions. J Inf Sci 2007; 33(2): 135-149.

[26] Jolaee A, Md Nor K, Khani N et al. Factors affecting knowledge sharing intention among academic staff. Int J Educ Manag 2014; 28(4): 413-431.

[27] Kim S and Lee H. The impact of organizational context and information technology on employee knowledge-sharing capabilities. Public Adm Rev 2006; 66(3): 370-385.

[28] Kang J, Rhee M and Kang KH. Revisiting knowledge transfer: effects of knowledge characteristics on organizational effort for knowledge transfer. Expert Syst Appl 2010; 37(12): 8155-8160.

[29] Kim S and Ju B. An analysis of faculty perceptions: attitudes toward knowledge sharing and collaboration in an academic institution. Libr Inf Sci Res 2008; 30(4): 282-290.

[30] Omerzel DG, Biloslavo R and Trnavcevic A. Knowledge management and organisational culture in higher education institutions. J East Eur Manag Stud 2011; 16(2): 111-139.

[31] Chedid M and Teixeira L. The knowledge management culture: an exploratory study in academic context. In: Deshpande DS, Bhosale N and Londhe RJ (eds) Enhancing academic research with knowledge management principles. Hershey, PA: IGI Global, 2017, pp. 1-24.

[32] Dill DD. The management of academic culture: notes on the management of meaning and social integration. High Educ 1982; 11(3): 303-320.

[33] Świgoń M. Knowledge and information sharing in the opinion of the Polish academic community. Int J Soc Behav Educ Econ Bus Ind Eng 2015; 9(4): 1057-1064.

[34] Gray B. Collaborating: finding common ground for multiparty problems. 1st ed. San Francisco, CA: Jossey-Bass Inc., 1989, pp. $1-329$.

[35] Diamond J and Rush L. Intra-organisational collaboration in one UK university: potential for change or missed opportunity. Int J Public Sect Manag 2012; 25(4): 287-300.

[36] Jakubik M. Experiencing collaborative knowledge creation processes. Learn Organ 2008; 15(1): 5-25.

[37] Freitas IMB and Verspagen B. The motivations, institutions and organization of university-industry collaborations in the Netherlands. J Evol Econ 2017; 27: 379-412. 
[38] Tian J, Nakamori Y, Xiang J et al. Knowledge management in academia: survey, analysis and perspective. Int J Manag Decis Mak 2006; 7(2-3): 275-294.

[39] Buckley S. Higher education and knowledge sharing: from ivory tower to twenty-first century. Innov Educ Teach Int 2012; 49(3): 333-344.

[40] Patel M and Ragsdell G. To share or not to share knowledge: an ethical dilemma for UK academics? J Knowl Manag Pract 2011; 12(2): 1-16.

[41] Bruneel J, D'Este P, Neely A and Salter A. The search for talent and technology - Examining the attitudes of EPSRC industrial collaborators towards universities. Advanced Institute of Management Research 2009; 1-48.

[42] Fishbein M and Ajzen I. Belief, attitude, intention, and behavior: an introduction to theory and research. Reading, MA: Addison-Wesley, 1975, p. 578.

[43] Deci EL, Olafsen AH and Ryan RM. Self-determination theory in work organizations: the state of a science. Annu Rev Organ Psychol Organ Behav 2017; 4: 19-43.

[44] Ajzen I and Fishbein M. The influence of attitudes on behavior. In: Albarracin D, Johnson BT and Zanna MP (eds) The handbook of attitudes. Mahwah, NJ: Lawrence Erlbaum Associates, 2005, pp. 173-222.

[45] Ryan RM and Deci EL. Intrinsic and extrinsic motivations: classic definitions and new directions. Contemp Educ Psychol 2000; 25(1): $54-67$.

[46] Deci EL and Ryan RM. Intrinsic motivation and self-determination in human behavior. New York: Plenum Press, $1985, \mathrm{p} .371$.

[47] Jafari Navimipour N and Charband Y. Knowledge sharing mechanisms and techniques in project teams: literature review, classification, and current trends. Comput Human Behav 2016; 62: 730-742.

[48] Bock GW and Kim YG. Breaking the myths of rewards: an exploratory study of attitudes about knowledge sharing. In: Proceedings of the Pacific Asia conference on information systems, 2001, pp. 1112-1125, https://aisel.aisnet.org/cgi/viewcontent.cgi?referer=https://search.yahoo.com/\&httpsredir=1\&article=1161\&context=pacis2001

[49] Yang C and Chen LC. Can organizational knowledge capabilities affect knowledge sharing behavior? J Inf Sci 2007; 33(1): 95109.

[50] Nonaka I, Toyama R and Nagata A. A firm as a knowledge-creating entity: a new perspective on the theory of the firm. Ind Corp Chang 2000; 9(1): 1-20.

[51] Avram G. At the crossroads of knowledge management and social software. Electron J Knowl Manag 2006; 4(1): 1-10.

[52] Du Chatenier E, Verstegen JAAM, Biemans HJA et al. The challenges of collaborative knowledge creation in open innovation teams. Hum Resour Dev Rev 2009; 8(3): 350-381.

[53] Argote L and Ingram P. Knowledge transfer: a basis for competitive advantage in firms. Organ Behav Hum Decis Process 2000; 82(1): 150-169.

[54] Nahapiet J and Ghoshal S. Social capital, intellectual capital, and the organizational advantage. Acad Manag Rev 1998; 23(2): $242-266$.

[55] Cormican K and Dooley L. Knowledge sharing in a collaborative networked environment. J Inf Knowl Manag 2007; 16(2): $105-115$.

[56] Riege A. Three-dozen knowledge-sharing barriers managers must consider. J Knowl Manag 2005; 9(3): 18-35.

[57] Bock GW, Zmud RW, Kim YG et al. Behavioral intention formation in knowledge sharing: examining the role of extrinsic motivators, social-psychological forces, and organizational climate. MIS Q 2005; 29(1): 87-112.

[58] Ford DP and Mason RM. A multilevel perspective of tensions between knowledge management and social media. $J$ Organ Comput Electron Commer 2013; 23(1-2): 7-33.

[59] Franco $\mathrm{M}$ and Haase H. University-industry cooperation: researchers' motivations and interaction channels. $J$ Eng Technol Manag 2015; 36: 41-51.

[60] Lin HF. Knowledge sharing and firm innovation capability: an empirical study. Int J Manpow 2007; 28(3-4): 315-332.

[61] Safa NS and Von Solms R. An information security knowledge sharing model in organizations. Comput Human Behav 2016; 57: 442-451.

[62] Igbaria M, Parasuraman S and Baroudi JJ. A motivational model of microcomputer usage. J Manag Inf Syst 1996; 13(1): 127143.

[63] Ajzen I and Fishbein M. Attitude-behavior relations: a theoretical analysis and review of empirical research. Psychol Bull 1977; 84(5): 888-918.

[64] Charband Y and Navimipour NJ. Online knowledge sharing mechanisms: a systematic review of the state of the art literature and recommendations for future research. Inf Syst Front 2016; 18: 1131-1151.

[65] Charband Y and Jafari Navimipour N. Knowledge sharing mechanisms in the education: a systematic review of the state of the art literature and recommendations for future research. Kybernetes 2018; 47(7): 1456-1490.

[66] Currall SC and Inkpen AC. On the complexity of organizational trust: a multi-level co-evolutionary perspective and guidelines for future research. In: Bachmann R, Zaheer A and Carlson CL (eds) The handbook of trust research. Cheltenham: Edward Elgar Publishing, 2006, pp. 235-246.

[67] Kuo TH. How expected benefit and trust influence knowledge sharing. Ind Manag Data Syst 2013; 113(4): 506-522.

[68] Świgoń M. Knowledge sharing practices in informal scholarly communication amongst academics in Poland. Malaysian J Libr Inf Sci 2017; 22(2): 101-115. 
[69] Wu L, Chuang $\mathrm{CH}$ and Hsu $\mathrm{CH}$. Information sharing and collaborative behaviors in enabling supply chain performance: a social exchange perspective. Int J Prod Econ 2014; 148: 122-132.

[70] Plessis M. The role of knowledge management in innovation. J Knowl Manag 2007; 11(4): 20-29.

[71] Ankrah S and Al-Tabbaa O. Universities-industry collaboration: a systematic review. Scand J Manag 2015; 31(3): $387-408$.

[72] Chin WW. How to write up and report PLS analyses. In: Esposito Vinzi V, Chin WW, Henseler J et al. (eds) Handbook of partial least squares. Berlin: Springer, 2010, pp. 655-690.

[73] Hair JF, Sarstedt M, Ringle CM et al. An assessment of the use of partial least squares structural equation modeling in marketing research. J Acad Mark Sci 2012; 40(3): $414-433$.

[74] Hair JF, Hult GTM, Ringle CM et al. A primer on partial least squares structural equation modeling (PLS-SEM). Thousand Oaks, CA: SAGE Publications, Inc., 2014, p. 307.

[75] Eusébio C, Carneiro MJ and Caldeira A. A structural equation model of tourism activities, social interaction and the impact of tourism on youth tourists' QOL. Int J Tour Policy 2016; 6(2): 85-108.

[76] Hair JF, Sarstedt M, Hopkins L et al. Partial least squares structural equation modeling (PLS-SEM): an emerging tool in business research. Eur Bus Rev 2014; 26(2): 106-121.

[77] Garson GD. Partial least squares: regression \& structural equation models. Asheboro, NC: Statistical Publishing Associates, 2016, p. 262.

[78] Bekkers R and Freitas IMB. Analysing knowledge transfer channels between universities and industry: to what degree do sectors also matter? Res Policy 2008; 37(10): 1837-1853.

[79] Likert R. A technique for the measurement of attitudes. Arch Psychol 1932; 22(140): 5-55.

[80] Adams J, Khan HTA, Raeside R et al. Research methods for graduate business and social science students. New Delhi, India: SAGE Publications, 2007, p. 270.

[81] Barclay DW, Higgins R and Thompson R. The partial least squares (PLS) approach to causal modeling: personal computer adoption and use as an illustration. Technol Stud Spec Issue Res Methodol 1995; 2: 285-309.

[82] Faul F, Erdfelder E, Lang AG et al. G*Power: a flexible statistical power analysis program for the social, behavioral, and biomedical sciences. Behav Res Methods 2007; 39(2): 175-191.

[83] Ringle CM, Da Silva D and Bido D. Structural equation modeling with the Smartpls. Rev Bras Mark 2014; $13(2)$ : 54-71.

[84] Fornell C and Larcker DF. Structural equation models with unobservable variables and measurement error. J Mark Res 1981; 18: $382-388$.

[85] Henseler J, Ringle CM and Sinkovics RR. The use of partial least squares path modeling in international marketing. In: Sinkovics RR and Ghauri PN (eds) New challenges to international marketing (Advances in international marketing), Vol. 20. Bingley: Emerald Group Publishing Limited, 2009, pp. 277-319.

[86] Henseler J, Ringle CM and Sarstedt M. A new criterion for assessing discriminant validity in variance-based structural equation modeling. J Acad Mark Sci 2015; 43(1): 115-135.

[87] Sporn B. Managing university culture: an analysis of the relationship between institutional culture and management approaches. High Educ 1996; 32(1): 41-61.

[88] Cook KS, Hardin R and Levi M. The significance of trust. In: Cook KS, Hardin R and Levi M (eds) Cooperation without trust? New York: Russell Sage Foundation, 2005, pp. 1-19.

[89] Ringle CM, Wende S and Becker J-M. SmartPLS 3 [Internet]. SmartPLS GmbH, Boenningsted, http://www.smartpls.com (2015, accessed 1 September 2017). 